\title{
MicroRNA-223 promotes mast cell apoptosis by targeting the insulin-like growth factor 1 receptor
}

\author{
HAIYAN GAO ${ }^{1,2^{*}}$, HUAN DENG $^{1 *}$, HONG XU $^{1}$, QIANYUAN YANG ${ }^{1}$, \\ YAO ZHOU $^{1}$, JIAMIN ZHANG ${ }^{1}$, DEYU ZHAO ${ }^{1}$ and FENG LIU ${ }^{1}$

\begin{abstract}
Department of Respiratory Medicine, Nanjing Children's Hospital Affiliated to Nanjing Medical University,
Nanjing, Jiangsu 210029; ${ }^{2}$ Department of Pediatrics, Huai'an First People's Hospital,

Nanjing Medical University, Huai'an, Jiangsu 223300, P.R. China
\end{abstract}

Received December 6, 2014; Accepted February 11, 2016

DOI: $10.3892 /$ etm.2016.3227

\begin{abstract}
The present study aimed to examine the functional role of miR-223 in the regulation of mast cell apoptosis. Overexpressed miR-223 in mast cells transfected by Lipofectamine 2000 was used as a model, and miR-223 was found to promote mast cell apoptosis. To investigate the underlying mechanisms involved, the potential and putative target molecules of miR-223 were detected by bioinformatical analysis using predictive software, and western blotting. Insulin-like growth factor-1 receptor (IGF-1R) was found to be the functional target of miR-223 in the promotion of cell apoptosis. The downstream PI3K/protein kinase B (Akt) signaling pathway was also inhibited, and signaling was mediated by IGF-1R. Furthermore, the relative luciferase activity of the reporter containing the 3'-untranslated region (3'-UTR) of IGF-1R was significantly suppressed, while suppression of miR-223-inhibited IGF-1R protein expression was also observed. In conclusion, the results suggest that IGF-1R is the functional target for miR-223 promotion of cell apoptosis, and its downstream PI3K/Akt signaling pathway was suppressed by miR-223 through targeting of IGF-1R.
\end{abstract}

\section{Introduction}

Mast cells, first identified by Paul Ehrlich in 1878, originate from multilineage hematopoietic progenitors that migrate to the organs and tissues and mature, ultimately residing under the

Correspondence to: Professor Deyu Zhao or Dr Feng Liu, Department of Respiratory Medicine, Nanjing Children's Hospital Affiliated to Nanjing Medical University, 72 Guangzhou Road, Nanjing, Jiangsu 210029, P.R. China

E-mail: zhaodeyu98@126.com

E-mail: axsliu@163.com

*Contributed equally

Key words: microRNA-223, insulin-like growth factor-1 receptor, mast cell, apoptosis effect of local cytokines and stem cell factor (1-4). Mast cells are predominantly localized at sites that are in close contact with the external environment, including the respiratory tract, gastrointestinal tract and skin. These cells function as important sentinel cells, which identify risk, and initiate and coordinate an inflammatory response following their activation (5-7). Mast cells are considered to be multifunctional cells that can be produced and stored, and specifically recognize and respond to various stimuli by releasing an array of biologically active mediators $(1,4)$. Therefore, mast cells participate in various biological processes, including the maintenance of homeostasis, angiogenesis, innate and adaptive immunity and immune tolerance. They also serve a significant role in several diseases, such as bronchial asthma, chronic skin inflammation (8), autoimmune diseases including rheumatoid arthritis $(2,9)$, atherosclerosis (10), cancer (11) and fibrotic diseases $(4,7)$. A correlation between disease severity and the number of mast cells has been previously identified in certain of the aforementioned diseases (2). Thus, controlling the mast cell numbers may serve as an attractive therapeutic intervention in mast cell-associated diseases, while a feasible strategy to counteract mast cell-dependent disease is to selectively induce mast cell apoptosis $(5,12,13)$. Mast cells have been demonstrated to serve a primary role in asthma (14), and previous studies have reported that miR-223 increased remarkably in the serum of children with asthma. Similar findings have been observed in an OVA-induced murine asthma model (15).

MicroRNAs (miRNAd or miRs) are a group of small, non-coding, single-stranded RNA molecules with a length of $\sim 22$ nucleotides. MiRNAs bind to the 3'-untranslated region (3'-UTR) of mRNAs, which then results in mRNA degradation or translational inhibition, thus post-transcriptionally regulating the translation of target genes (16-19). These target genes regulate a wide variety of biological processes, including differentiation, proliferation, maturation, apoptosis and tumorigenesis (16-19).

Insulin-like growth factor 1 receptor (IGF-1R) is a transmembrane receptor tyrosine kinase that is widely expressed in numerous cell lines and cell types, which is very important for cellular proliferation in vivo. The primary components of the IGF-1R pathway include IGF-1R and its highly structurally conserved family member, the insulin receptor. Both receptors consist of two half-receptors, each comprising one extracellular $\alpha$-subunit and one transmembrane $\beta$-subunit that 
possesses tyrosine kinase activity. IGF-1R signaling cascades begin at the cell surface with IGF ligands (IGF-1 and IGF-2) binding to several transmembrane receptors, namely IGF-1R, IGF-2R and the IR, which serves an important role in cell growth, transformation, and the protection of cells from a variety of apoptotic stimuli (20-23). The relationship between microRNA and IGF-1R has attracted increasing attention. It has been reported that miR-7 (24), miR-320a (25) and miR-503 (26) modulate glioma cell functions including proliferation, apoptosis, migration, invasion and tumorigenesis by targeting IGF-1R. In addition, researches have demonstrated that upregulation of miR-150, miR-630 (27) and miR-497 (28) inhibit cell proliferation and enhance apoptosis in pancreatic cancer cells by targeting IGF-1R. More importantly, studies have confirmed that miR-223 serves an important role in cell proliferation and apoptosis by targeting the IGF-1R in other cell types $(19,29)$.

Apoptosis regulated by a specific gene is also known as programmed cell death. Previous studies have confirmed several components via which mast cell apoptosis is regulated, including growth factors, monomeric IgE, Toll-like receptors, tumor necrosis factor- $\alpha$ receptors and proteins of the Bcl-2 family $(2,30)$. However, the underlying mechanism via which miR-223 regulates the apoptosis of mast cells remains unclear. In the present study, the role of miR-223 in cell apoptosis was investigated to determine the potential mechanism by which the miR-223-induced increase in cell apoptosis is mediated.

\section{Materials and methods}

Cell culture and transfection. Rat basophilic leukemia (RBL) cells were obtained from the Shanghai Institute of Biochemistry and Cell Biology (Chinese Academy of Science, Beijing, China). The RBL cells, were cultured in Eagle's minimal essential medium (EMEM) supplemented with $10 \%$ fetal bovine serum (FBS; Thermo Fisher Scientific, Inc. Carlsbad, CA, USA). The cells were incubated at $37^{\circ} \mathrm{C}$ in a humidified atmosphere supplemented with $5 \% \mathrm{CO}_{2}$. The cells were transfected with an miR-223 mimic the following day by seeding using Lipofectamine 2000 (Thermo Fisher Scientific, Inc.). Lipofectamine 2000 alone was used as the control (empty vector). In order to induce miR-223 overexpression, $50 \mathrm{nM}$ miR-223 mimic was used (Thermo Fisher Scientific, Inc.). The cells were harvested $24 \mathrm{~h}$ after transfection, and total RNA was extracted for reverse transcription-quantitative polymerase chain reaction (RT-qPCR) analysis. Furthermore, cell lysates were prepared for western blotting. Cell apoptosis assays were also performed subsequent to inducing serum starvation for $24 \mathrm{~h}$.

$R T$ - $q P C R$. Total RNA was extracted from RBL cells using TRIzol reagent (Invitrogen; Thermo Fisher Scientific, Inc.). Next, total RNA was reverse transcribed into cDNA using a TaqMan MicroRNA Reverse Transcription Kit (Applied Biosystems; Thermo Fisher Scientific, Inc.) according to the manufacturer's instructions. qPCR was performed using an Applied Biosystems 7500 Fast Real-Time PCR system (Thermo Fisher Scientific, Inc.) and a TaqMan MicroRNA Assay (Applied Biosystems; Thermo Fisher Scientific, Inc.). The following thermal conditions were used for all qPCR reactions: Amplification at $95^{\circ} \mathrm{C}$ for $5 \mathrm{~min}, 40$ cycles at $95^{\circ} \mathrm{C}$ for $10 \mathrm{sec}$, at $60^{\circ} \mathrm{C}$ for $30 \mathrm{sec}$ and at $72^{\circ} \mathrm{C}$ for $10 \mathrm{sec}$. All reactions were performed in triplicate with a final volume of $20 \mu \mathrm{l}$ (10 $\mu \mathrm{l}$ TaqMan master mix, $1 \mu \mathrm{l} \mathrm{cDNA,} 1 \mu \mathrm{l}$ miR-223/U6RNA probe and $8 \mu \mathrm{l}$ diethylpyrocarbonate). The primers used in the PCR experiment were as follows: miR-223 forward, 5'-GTG CAGGGTCCGAGGT-3', and reverse, 5'-CGGGCTGTC AGTTTGTCA-3'; U6RNA forward, 5'-CTCGCTTCGGCA GCACA-3', and reverse, 5'-AACGCTTCACGAATTTGC GT-3'. The miRNA expression was determined using the $2^{-\Delta \Delta C q}$ method (31). U6RNA (Invitrogen; Thermo Fisher Scientific, Inc.) was used as an internal control.

Transfection. RBL cells were plated into a 96-well plate at a density of 3,000 cells/well; Lipofectamine 2000 was used as the vector, and RBL cells were transfected with an miR-223 mimic. Briefly, one day prior to transfection, RBL cells were placed in EMEM supplemented with 10\% FBS until 30-50\% confluence. For miR-223 overexpression, $50 \mathrm{nM}$ mimic miR-223 was used. Cells were incubated at $37^{\circ} \mathrm{C}$ in a $\mathrm{CO}_{2}$ incubator for 24-48 h; the growth medium was replaced of EMEM supplemented with 10\% FBS after 4-6 h.

Cell viability assay. RBL cells were transfected with $50 \mathrm{nM}$ miR-223 mimics, and cell viability was assessed $24 \mathrm{~h}$ post-transfection after serum starvation for $24 \mathrm{~h}$. For the cell viability assay, $10 \mu \mathrm{l}$ Cell Counting Kit-8 (CCK-8; Dojindo Molecular Technologies, Inc., Kumamoto, Japan) solution was added to each well of 96-well plates (3,000 cells/well) and the plates were incubated for $1 \mathrm{~h}$ with EMEM supplemented with $10 \%$ FBS. The optical density (OD) at $450 \mathrm{~nm}$ was recorded using a microplate reader (DNM-9602; Beijing Perlong New Technology Co., Ltd., Beijing, China). The OD value representing the cell viability and number in each group was calculated and summarized based on the results of three independent experiments.

Apoptosis assay. Apoptosis of RBL cells was detected using an Annexin V-fluorescein isothiocyanate (FITC)/propidium-iodide (PI) staining assay. In order to induce cell apoptosis, the cells were grown to $50-60 \%$ confluence, then washed twice with FBS-free EMEM and starved in EMEM without $10 \%$ FBS for $24 \mathrm{~h}$. Flow cytometric analysis of apoptotic cells was performed using a FITC Annexin V Apoptosis Detection Kit I (BD Biosciences; Franklin Lakes, NJ, USA). Subsequent to washing with cold phosphate buffered saline (PBS), the cells were resuspended in binding buffer and stained with Annexin V-FITC/PI for 15 min in darkness at room temperature. Apoptotic cells were then evaluated by gating PI- and Annexin V-positive cells on a BD FACSCalibur flow cytometer (BD Biosciences). All the experiments were performed in triplicate. The distribution of cells was analyzed using Cell Quest Pro software (version 4.01; BD Biosciences) within $1 \mathrm{~h}$ of staining. Data from 10,000 cells were collected for each data file, and the number of cells in each category was expressed as a percentage of the total number of stained cells.

Dual luciferase reporter assay. A luciferase reporter assay was performed on HEK-293T cells (Shanghai Institute of 
Biochemistry and Cell Biology (Chinese Academy of Science) in order to confirm that IGF-1R is the target gene of miR-223. At $48 \mathrm{~h}$ after transfection, the transfected cells were lysed using $100 \mu \mathrm{l}$ passive lysis buffer (Promega Corp., Madison, WI, USA), subsequent to washing twice in PBS. Next, $20 \mu 1$ lysate was used to measure the luciferase activity with a Dual-Luciferase Reporter Assay system (Promega Corp.). The data were calculated based on the results of four independent experiments. The mutated psiCHECK ${ }^{\mathrm{TM}}-2-\mathrm{IGF}-1 \mathrm{R}$ 3'-UTR (China Anping Kang Biological Technology Co., Ltd., Shenzhen, China) was also transfected under the same conditions. Subsequently, the miR-223 inhibitor and the control were used at a final concentration of $100 \mathrm{nM}$ in order to determine the inhibitory effect of miR-223 on the 3'-UTR of IGF-1R.

Western blot analysis. RBL cells were cultured in 6-well plates $\left(3 \times 10^{5}\right.$ cells/well) and lysed in ice-cold radioimmunoprecipitation assay buffer (Beyotime Institute of Biotechnology, Nantong, China). The total protein concentration was determined using an enhanced BCA protein assay kit (Beyotime Institute of Biotechnology). An equal amount of protein was then separated by $10 \%$ sodium dodecyl sulfate-polyacrylamide gel electrophoresis and transferred onto nitrocellulose filter membranes (Merck Millipore, Billerica, MA, USA). Next, the blots were blocked with 5.0\% non-fat milk in PBS with Tween 20 (PBST) for $2 \mathrm{~h}$ at room temperature. The blots were then incubated overnight at $4^{\circ} \mathrm{C}$ with specific primary antibodies against the following: IGF-1R (rabbit monoclonal; 9750), protein kinase B (Akt; rabbit polyclonal; 9272) and phosphorylated-Akt (Ser473; p-Akt; rabbit monoclonal; 4060) at dilutions of 1:1,000, 1:1,000 and 1:2,000 (all three from Cell Signaling Technology, Inc., Beverly, MA, USA); and B-cell lymphoma-2 (Bcl-2; dilution, 1:200; sc-7382) and GAPDH (rabbit polyclonal; dilution, 1:1,000; sc-25778) (both purchased from Santa Cruz Biotechnology, Inc., Dallas, TX, USA). Subsequently, the membranes were washed three times with PBST and then incubated with horseradish peroxidase-conjugated goat anti-rabbit or anti-mouse antibodies (1:5,000; ZB-2305; Zhongshan Golden Bridge Biotechnology Co., Ltd., Zhongshan, China) for $2 \mathrm{~h}$ at room temperature. Signals were detected on a gel imaging system using the Pierce ECL Western blotting substrate (Thermo Fisher Scientific, Inc., Waltham, MA, USA).

Statistical analysis. Data were analyzed using SPSS software version 20.0 (IBM Corp., Armonk, NY, USA). The Student's t-test was used for the analysis of statistical differences between two independent groups. Quantitative data are expressed as the mean \pm standard deviation of at least three independent experiments. Differences were considered as statistically significant at $\mathrm{P}<0.05$.

\section{Results}

Upregulation of miR-223 in mast cells. In order to elucidate the role of miR-223 in mast cells, a model of overexpressed miR-223 was established by transfecting the cells with miR-223 mimics using Lipofectamine 2000. Subsequently, in order to identify miR-223 expression in mast cells, RT-qPCR was performed, and the results showed that miR-223 expression
Table I. miR-223 overexpressed in mast cells.

\begin{tabular}{lccc}
\hline Group & miRNA & Fold change & P-value \\
\hline Control & miR-223 & 1.08 & \\
miR-223 & miR-223 & 3549.66 & $<0.001$ \\
\hline
\end{tabular}

miR, microRNA.

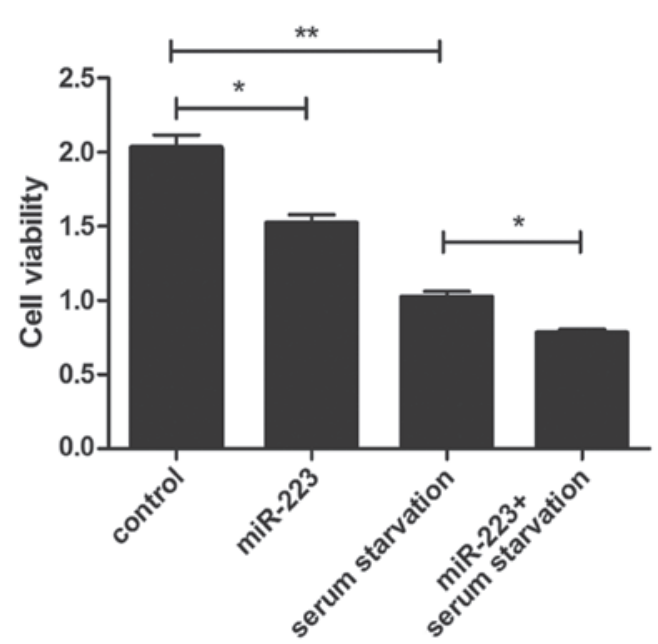

Figure 1. Effect of miR-223 on mast cell viability. Cells were transfected with $50 \mathrm{nM}$ miR-223 mimics and cell viability was assessed $24 \mathrm{~h}$ post-transfection after serum starvation for $24 \mathrm{~h}$ using the cell counting kit- 8 . Results are expressed as the mean \pm standard deviation. ( ${ }^{* *} \mathrm{P}<0.01$; $\left.{ }^{*} \mathrm{P}<0.05 ; \mathrm{n}=5\right)$. miR, microRNA.

was significantly higher in cells transfected with miR-223 compared with the expression in the control group (Table I).

miR-223 suppression of mast cell viability. A CCK-8 assay was performed in order to investigate the viability of mast cells. At $24 \mathrm{~h}$ after serum starvation, a significant decrease in cell viability was detected when compared with that in the control group (Fig. 1). As shown in Fig. 1, the cell viability was decreased in the miR-223 group compared with that in the control group, and the same result was observed for the miR-223-transfected cells under the serum starvation conditions.

miR-223 promotes cell apoptosis. To detect the effect of miR-223 on the apoptosis of mast cells, a cytofluorometric apoptosis assay was performed and the flow cytometry results are shown in Fig. 2A. Previous studies have shown that serum starvation can effectively induce cell apoptosis $(32,33)$. In the current study, serum starvation conditions were induced on cultured mast cells for $24 \mathrm{~h}$ in order to initiate cell apoptosis. As shown in Fig. 2B, incubation of the cells with miR-223 significantly increased the serum starvation-induced apoptosis of mast cells.

$I G F-1 R$ is targeted by $m i R-223$. An increasing number of studies are investigating IGF-1R, which has been demonstrated to serve a significant role in the regulation of cell proliferation and apoptosis (34-37). Therefore, in order to further investigate the underlying mechanism through which miR-223 promotes the apoptosis of mast cells, IGF-1R was 

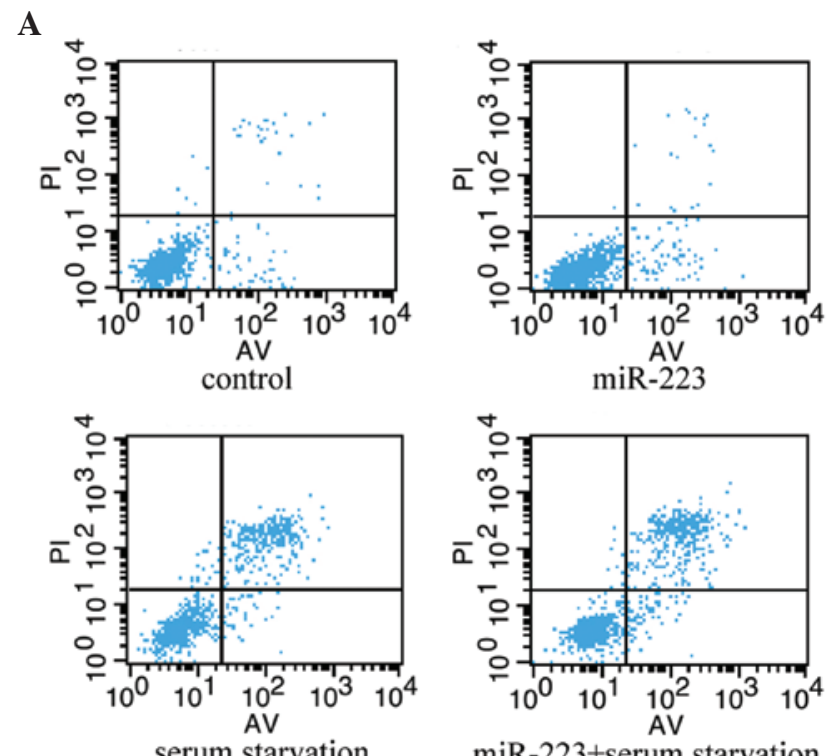

B

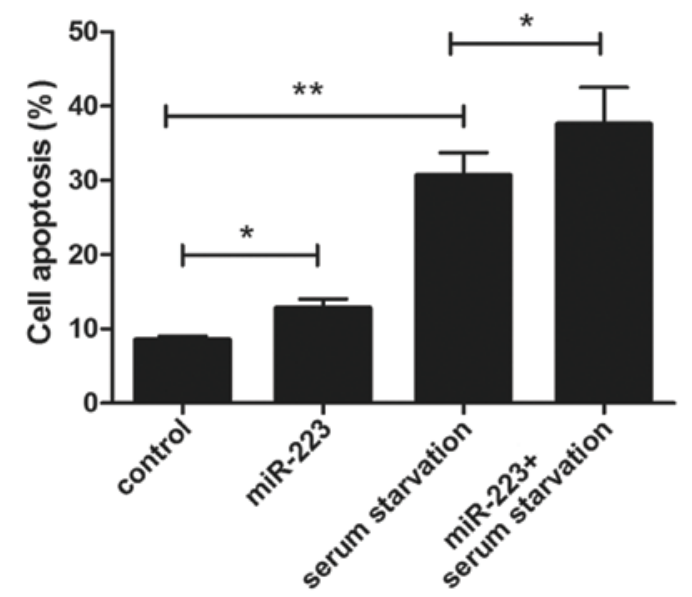

Figure 2. Upregulation of miR-223 expression induces mast cell apoptosis. (A) Post-transfection with miR-223, cells were stained with Annexin-V-FITC and propidium iodide, followed by flow cytometry. (B) Representation of average apoptotic cell fractions (early and late apoptosis cells) in each group for three independent experiments. $\left({ }^{* *} \mathrm{P}<0.01\right.$; $\left.{ }^{*} \mathrm{P}<0.05 ; \mathrm{n}=5\right)$. miR, miRNA.

selected in the present study. The results demonstrated that the IGF-1R protein expression levels, as detected by western blotting, decreased in the cells overexpressing miR-223 compared with those in the control group (Fig. 3A). A 3'-UTR reporter assay was then conducted to determine whether miR-223 binds to the 3'-UTR of IGF-1R. The results showed a decrease in luciferase activity in the cells transfected with an miR-223 expression vector compared with the cells transfected with the control vector (Fig. 3B), indicating that IGF-1R was inhibited in IGF-1R 3'-UTR by miR-223.

miR-223 inhibition of PI3K/Akt signaling pathway. The expression levels of Akt, an essential protein kinase in the PI3K/Akt signaling pathway downstream of IGF-1R, and of its active form (p-Akt) were determined to assess whether the IGF-1R-mediated downstream signaling pathway was also inhibited by miR-223. The results revealed that the expression of $\mathrm{p}$-Akt was significantly decreased compared with that of the control group; however, the expression of total Akt was unaffected (Fig. 4).
A

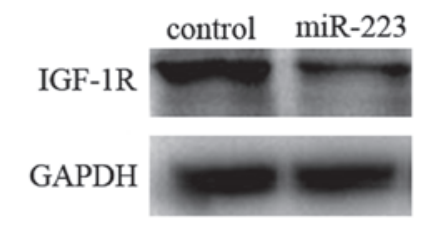

B

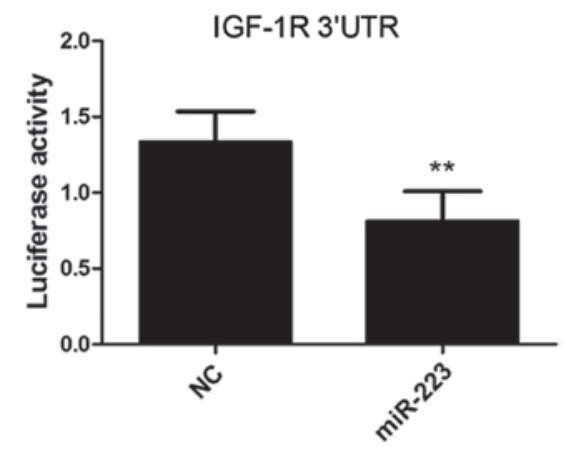

Figure 3. IGF-1R targeted by miR-223. (A) IGF-1R protein expression, detected by western blotting, decreased in the miR-223-overexpression group compared with that in the control group. (B) Luciferase activity decreased in cells overexpressing miR-223 compared with that in the control group $\left({ }^{* *} \mathrm{P}<0.01\right)$. IGF-1R, insulin-like growth factor 1 receptor; miR, microRNA.

A

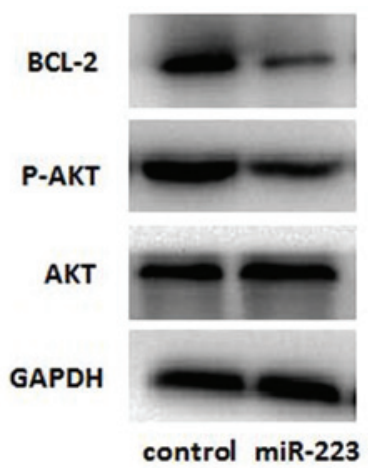

B

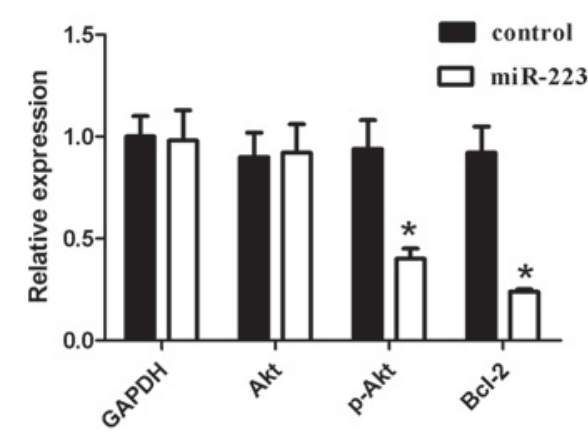

Figure 4. miR-223 negatively regulates the PI3K/Akt signaling pathway. (A) Western blotting was used to detect the expression levels of Akt, p-Akt, and Bcl-2 in cells transfected with miR-223. GAPDH was used as a loading control. (B) Data were normalized to GAPDH expression and presented as a percentage of the expression level in untreated cellular controls. Data are presented as the mean \pm standard deviation. ${ }^{*} \mathrm{P}<0.01$ vs. control. miR, microRNA; Akt, protein kinase B; p-, phosphorylated; Bcl-2, B-cell lymphoma-2.

Furthermore, Bcl-2 (an anti-apoptotic regulator) is one of the downstream molecules, which are normally promoted by p-Akt. In the present study, the protein expression of Bcl-2 was 
downregulated upon miR-223 transfection, when compared with that in the control group (Fig. 4).

\section{Discussion}

In the present study, increasing apoptosis was observed in mast cells with an overexpression of miR-223. miRNAs serve a vital regulatory role in various biological processes by targeting mRNAs for cleavage or translational repression $(16,19)$. In recent years, accumulating evidence has demonstrated that the myeloid-specific miR-223 can affect multiple targets and modulate different cellular processes, ranging from the regulation of cell proliferation and cancer development to hematopoietic differentiation, particularly in myeloid lineage development, and immune cell function (38-40). A number of studies have demonstrated that miR-223, an evolutionarily conserved miRNA, may represent a potential biomarker for various diseases, including recurrent ovarian cancer (41), psoriasis (42) and bladder cancer (43). It was also reported that miR-223 functions as an oncogene in human colorectal cancer (CRC) cells, and reducing the miR-223 expression may result in decreased cell proliferation, migration and invasion of CRC cells (44). Therefore, elevated expression of miR-223 leads to a poor prognosis in patients with CRC (45). Similar effects have been observed in osteosarcoma $(46,47)$ and Helicobacter pylori-associated gastric cancer (48). Furthermore, studies have confirmed that miR-223 targets the transcription factor CEBP- $\alpha$ (49), glutamate receptors (GluR2 and NR2B) (50), stathmin1 (51) and IGF-1R (52), contributing to the biological function in other cell types.

Two pathways are known to be involved in regulating mast cell apoptosis: The extrinsic and the intrinsic pathways. The $\mathrm{Bcl}-2$ protein family plays a key role in the intrinsic pathway of apoptosis (2). This protein family contains pro- and anti-apoptotic members, and the balance between these members determines cell survival and apoptosis (5). As shown in Fig. 4, the expression of $\mathrm{Bcl}-2$ protein decreased in cells overexpressing miR-223 when compared with that in the control cells. In addition, identification of the pro-apoptotic Bcl-2 homology 3-only proteins has also been reported, including p53 upregulated modulator of apoptosis and Bcl-2-like 11, which are critical for the induction of mast cell apoptosis following cytokine deprivation $(2,12)$. Furthermore, mast cell apoptosis can be triggered by tumor necrosis factor-related apoptosis-inducing ligand receptor, which is involved in the extrinsic pathway of apoptosis (2). Therefore, induction of apoptosis may provide a novel intervention by disrupting the development of mast cell-associated disorders.

In the present study, a model of miR-223 overexpression was established by transfecting cells using Lipofectamine 2000, and the miR-223 suppression of proliferation and promotion of apoptosis was observed in mast cells. The present results suggest that miR-223 functioned as a negative regulator of cell growth. In order to determine the underlying mechanisms and target genes that were responsible for the suppressive function of miR-223, a luciferase reporter assay was performed. The results demonstrated that overexpression of miR-223 resulted in a significant decrease in the luciferase activity of the IGF-1R-3'-UTR reporter. Furthermore, western blotting detected that the IGF-1R protein expression was significantly downregulated following overexpression of miR-223 in cells. All the aforementioned results indicate that IGF-1R is a functional target gene of miR-223.

The IGF-1R signaling pathway is involved in the normal growth and development of cells, and serves a crucial role in the regulation of cell proliferation following IGF-1 binding to IGF-1R through activation of the PI3K/Akt signaling pathway (52-54). The upstream PI3K/Akt signaling pathway has been shown to mediate dynamic changes in the actin cytoskeleton, integrin signaling and cell survival $(37,55)$. The $\mathrm{PI} 3 \mathrm{~K} / \mathrm{Akt}$ signaling pathway is important in miR-223 regulation of cell apoptosis, and the results of the present study showed that the PI3K/Akt signaling pathway was suppressed by overexpression of miR-223, which is consistent with bioinformatical predictions. The current study revealed that miR-223 regulates the apoptosis of mast cells by targeting IGF-1R and its downstream PI3K/Akt signaling pathway.

In conclusion, the present study indicated that increasing the expression of miR-223 can promote apoptosis in mast cells. IGF-1R, as the target gene of miR-223, and the PI3K/Akt signaling pathway were found to be involved in the regulation of mast cell apoptosis.

\section{Acknowledgements}

The current research was supported by the National Natural Science Foundation of China (grant no. 81200012; awarded to Feng Liu) and the National Natural Science Foundation of China (grand no. 81370132; awarded to Deyu Zhao). The authors would also like to thank the Medical School of Nanjing University for its technical support.

\section{References}

1. da Silva EZ, Jamur MC and Oliver C: Mast cell function: A new vision of an old cell. J Histochem Cytochem 62: 698-738, 2014.

2. Ekoff M and Nilsson G: Mast cell apoptosis and survival. Adv Exp Med Biol 716: 47-60, 2011.

3. Valent P, Akin C, Arock M, Brockow K, Butterfield JH, Carter MC, Castells M, Escribano L, Hartmann K, Lieberman P, et al: Definitions, criteria and global classification of mast cell disorders with special reference to mast cell activation syndromes: A consensus proposal. Int Arch Allergy Immunol 157: 215-225, 2012.

4. Wygrecka M, Dahal BK, Kosanovic D, Petersen F, Taborski B, von Gerlach S, Didiasova M, Zakrzewicz D, Preissner KT, Schermuly RT and Markart P: Mast cells and fibroblasts work in concert to aggravate pulmonary fibrosis: Role of transmembrane SCF and the PAR-2/PKC-alpha/Raf-1/p44/42 signaling pathway. Am J Pathol 182: 2094-2108, 2013.

5. Karlberg M, Ekoff M, Huang DC, Mustonen P, Harvima IT and Nilsson G: The BH3-mimetic ABT-737 induces mast cell apoptosis in vitro and in vivo: Potential for therapeutics. J Immunol 185: 2555-2562, 2010.

6. Picard M, Giavina-Bianchi P, Mezzano V and Castells M: Expanding spectrum of mast cell activation disorders: Monoclonal and idiopathic mast cell activation syndromes. Clin Ther 35: 548-562, 2013.

7. Overed-Sayer C, Rapley L, Mustelin T and Clarke DL: Are mast cells instrumental for fibrotic diseases? Front Pharmacol 4: 174, 2014.

8. Harvima IT and Nilsson G: Stress, the neuroendocrine system and mast cells: Current understanding of their role in psoriasis. Expert Rev Clin Immunol 8: 235-241, 2012.

9. Benoist $C$ and Mathis D: Mast cells in autoimmune disease. Nature 420: 875-878, 2002.

10. Sun J, Sukhova GK, Wolters PJ, Yang M, Kitamoto S, Libby P, MacFarlane LA, Mallen-St Clair J and Shi GP: Mast cells promote atherosclerosis by releasing proinflammatory cytokines. Nat Med 13: 719-724, 2007. 
11. Soucek L, Lawlor ER, Soto D, Shchors K, Swigart LB and Evan GI: Mast cells are required for angiogenesis and macroscopic expansion of Myc-induced pancreatic islet tumors. Nat Med 13: 1211-1218, 2007.

12. Melo FR, Waern I, Rönnberg E, Åbrink M, Lee DM, Schlenner SM Feyerabend TB, Rodewald HR, Turk B, Wernersson S and Pejler G: A role for serglycin proteoglycan in mast cell apoptosis induced by a secretory granule-mediated pathway. J Biol Chem 286: 5423-5433, 2011.

13. Lessene G, Czabotar PE and Colman PM: BCL-2 family antagonists for cancer therapy. Nat Rev Drug Discov 7: 989-1000, 2008.

14. Bradding P, Walls AF and Holgate ST: The role of the mast cell in the pathophysiology of asthma. J Allergy Clin Immunol 117: $1277-1284,2006$

15. Xu C, Mei J, Li D, Liu J, Qin H, Liu F and Zhao D: Expression of microRNA in murine model induced by ovalbumin. Shi Yong Er Ke Lin Chuang Za Zhi 21: 1655-1657, 2012 (In Chinese).

16. Bartel DP: MicroRNAs: Genomics, biogenesis, mechanism, and function. Cell 116: 281-297, 2004.

17. Ebert MS and Sharp PA: Roles for microRNAs in conferring robustness to biological processes. Cell 149: 515-524, 2012.

18. Winter J, Jung S, Keller S, Gregory RI and Diederichs S: Many roads to maturity: MicroRNA biogenesis pathways and their regulation. Nat Cell Biol 11: 228-234, 2009.

19. Pan Y, Liang H, Liu H, Li D, Chen X, Li L, Zhang CY and Zen K: Platelet-secreted microRNA-223 promotes endothelial cell apoptosis induced by advanced glycation end products via targeting the insulin-like growth factor 1 receptor. J Immunol 192: 437-446, 2014.

20. LeRoith D and Roberts CT Jr: The insulin-like growth factor system and cancer. Cancer Lett 195: 127-137, 2003.

21. Pollak MN, Schernhammer ES and Hankinson SE: Insulin-like growth factors and neoplasia. Nat Rev Cancer 4: 505-518, 2004.

22. Samani AA, Yakar S, LeRoith D and Brodt P: The role of the IGF system in cancer growth and metastasis: Overview and recent insights. Endocr Rev 28: 20-47, 2007.

23. Adams TE, Epa VC, Garrett TP and Ward CW: Structure and function of the type 1 insulin-like growth factor receptor. Cell Mol Life Sci 57: 1050-1093, 2000.

24. Wang B, Sun F, Dong N, Sun Z, Diao Y, Zheng C, Sun J, Yang Y and Jiang D: MicroRNA-7 directly targets insulin-like growth factor 1 receptor to inhibit cellular growth and glucose metabolism in gliomas. Diagn Pathol 19: 211, 2014.

25. Guo T, Feng Y, Liu Q, Yang X, Jiang T, Chen Y, Zhang Q: MicroRNA-320a suppresses in GBM patients and modulates glioma cell functions by targeting IGF-1R. Tumor Biol 35: 11269-11275, 2014.

26. Zhang Y, Chen X, Lian H, Liu J, Zhou B, Han S, Peng B, Yin J, Liu W and He X: MicroRNA-503 acts as a tumor suppressor in glioblastoma for multiple antitumor effects by targeting IGF-1R Oncology Reports 31: 1445-1452, 2014.

27. Farhana L, Dawson MI, Murshed F, Das JK, Rishi AK, Fontana JA: Upregulation of miR-150* and miR-630 induces apoptosis in pancreatic cancer cells by targeting IGF-1R. PLoS One 8: e61015, 2013.

28. Xu JW, Wang TX, You L, Zheng LF, Shu H, Zhang TP and Zhao YP: Iusulin-like growth factor 1 receptor (IGF-1R) as a target of miR-497 and plasma IGF-1R levels associated with TNM stage of pancreatic cancer. PloS One 9: e92847, 2014.

29. Huang K, Dong X, Sui C, Hu D, Xiong T, Liao S, Zhang H: MiR-223 suppresses endometrial carcinoma cells proliferation by targeting IGF-1R. Am J Transl Res 6: 841-849, 2014.

30. Gerbaulet A, Hartmann K and Mekori YA: Mast cell apoptosis. Methods Mol Biol 315: 407-423, 2006.

31. Livak KJ and Schmittgen TD: Analysis of relative gene expression data using real-time quantitative PCR and the $2^{-\Delta \Delta C t}$ method. Methods 25: 402-408, 2001

32. Hara K, Ueda S, Ohno Y, Tanaka T, Yagi H, Okazaki S, Kawahara R, Masayuki T, Enomoto T, Hashimoto Y, et al: NIH3T3 cells overexpressing CD98 heavy chain resist early G1 arrest and apoptosis induced by serum starvation. Cancer Sci 103: 1460-1466, 2012.

33. Liang W, Ye D, Dai L, Shen Y and Xuu J: Overexpression of hTERT extends replicative capacity of human nucleus pulposus cells, and protects against serum starvation-induced apoptosis and cell cycle arrest. J Cell Biochem 113: 2112-2121, 2012.

34. Chen J, Hou R, Zhang X, Ye Y, Wang Y and Tian J: Calycosin suppresses breast cancer cell growth via ER $\beta$-dependent regulation of IGF-1R, p38 MAPK and PI3K/Akt pathways. PloS One 9: e91245, 2012.
35. Ohtani M, Numazaki M, Yajima Y and Fujita-Yamaguchi Y: Mechanisms of antibody-mediated insulin-like growth factor I receptor (IGF-IR) down-regulation in MCF-7 breast cancers. Biosci Trends 3: 131-138, 2009.

36. Zhao Y, Wang Z, Jiang Y and Yang C: Inactivation of Rac 1 reduces Trastuzumab resistance in PTEN deficient and insulin-like growth factor I receptor overexpressing human breast cancer SKBR3 cells. Cancer Lett 313: 54-63, 2011.

37. Pollak M: The insulin and insulin-like growth factor receptor family in neoplasia: An update. Nat Rev Cancer 12: 159-169, 2012.

38. Johnnidis JB, Harris MH, Wheeler RT, Stehling-Sun S, Lam MH, Kirak O, Brummelkamp TR, Fleming MD and Camargo FD: Regulation of progenitor cell proliferation and granulocyte function by microRNA-223. Nature 451: 1125-1129, 2008 .

39. Haneklaus M, Gerlic M, O'Neill LA and Masters SL: MiR-223. Infection, inflammation and cancer. J Intern Med 274: 215-226, 2013.

40. Vian L, Di Carlo M, Pelosi E, Fazi F, Santoro S, Cerio AM, Boe A, Rotilio V, Billi M, Racanicchi S, et al: Transcriptional fine-tuning of microRNA-223 levels directs lineage choice of human hematopoietic progenitors. Cell Death Differ 21: 290-301, 2014.

41. Laios A, O'Toole S, Flavin R, Martin C, Kelly L, Ring M, Finn SP, Barrett C, Loda M, Gleeson N, et al: Potential role of miR-9 and miR-223 in recurrent ovarian cancer. Mol Cancer 7: 35, 2008.

42. Løvendorf MB,Zibert JR, Gyldenløve M, Røpke MA and Skov L: MicroRNA-223 and miR-143 are important systemic biomarkers for disease activity in psoriasis. J Dermatol Sci 75: 133-139, 2014

43. Gottardo F, Liu CG, Ferracin M, Calin GA, Fassan M, Bassi P, Sevignani C, Byrne D, Negrini M, Pagano F, et al: Micro-RNA profiling in kidney and bladder cancers. Urol Oncol 25: 387-392, 2007.

44. Zhang J, Luo X, Li H, Yue X, Deng L, Cui Y and Lu Y: MicroRNA-223 functions as an oncogene in human colorectal cancer cells. Oncol Rep 32: 115-120, 2014.

45. Li ZW, Yang YM, Du LT, Dong Z, Wang LL, Zhang X, Zhou XJ, Zheng GX, Qu AL and Wang CX: Overexpression of miR-223 correlates with tumor metastasis and poor prognosis in patients with colorectal cancer. Med Oncol 31: 256, 2014.

46. Zhang H, Yin Z, Ning K, Wang L, Guo R and Ji Z: Prognostic value of microRNA-223/epithelial cell transforming sequence 2 signaling in patients with osteosarcoma. Hum Pathol 45: 1430-1436, 2014

47. Li G, Cai M, Fu D, Chen K, Sun M, Cai Z and Cheng B: Heat shock protein $90 \mathrm{~B} 1$ plays an oncogenic role and is a target of microRNA-223 in human osteosarcoma. Cell Physiol Biochem 30: 1481-1490, 2012.

48. Ma L, Chen Y, Zhang B and Liu G: Increased microRNA-223 in Helicobacter pylori-associated gastric cancer contributed to cancer cell proliferation and migration. Biosci Biotechnol Biochem 78: 602-608, 2014.

49. Pulikkan JA, Dengler V, Peramangalam PS, Peer Zada AA, Müller-Tidow C, Bohlander SK, Tenen DG and Behre G: Cell-cycle regulator E2F1 and microRNA-223 comprise an autoregulatory negative feedback loop in acute myeloid leukemia. Blood 115: 1768-1778, 2010.

50. Harraz MM, Eacker SM, Wang X, Dawson TM and Dawson VL: MicroRNA-223 is neuroprotective by targeting glutamate receptors. Proc Natl Acad Sci USA 109: 18962-18967, 2012.

51. Kang W, Tong JH, Chan AW, Lung RW, Chau SL, Wong QW, Wong N, Yu J, Cheng AS and To KF: Stathmin1 plays oncogenic role and is a target of microRNA-223 in gastric cancer. PLoS One 7: e33919, 2012

52. Jia CY, Li HH, Zhu XC, Dong YW, Fu D, Zhao QL, Wu W and Wu XZ: MiR-223 suppresses cell proliferation by targeting IGF-1R. PLoS One 6: e27008, 2011.

53. Wu LH, Cai QQ, Dong YW, Wang R, He BM, Qi B, Xu CJ and Wu XZ: Decoy oligonucleotide rescues IGF1R expression from MicroRNA-223 suppression. PLoS One 8: e82167, 2013.

54. Yu YH, Zhang L, Wu DS, Zhang Z, Huang FF, Zhang J, Chen XP, Liang DS, Zeng $\mathrm{H}$ and Chen FP: MiR-223 regulates human embryonic stem cell differentiation by targeting the IGF-1R/Akt signaling pathway. PLoS One 8: e78769, 2013.

55. Rodriguez-Viciana P, Warner PH, Khwaja A, Marte BM, Pappin D, Das P, Waterfield MD, Ridley A and Downward J: Role of phosphoinositide 3-OH kinase in cell transformation and control of the actin cytoskeleton by Ras. Cell 89: 457-467, 1997. 